\title{
路易斯碱有机小分子催化亚胺的不对称还原研究进展
}

\author{
葛 新 $a, b$ 陈新志 $b$ 钱 超 $*, b$ \\ ( ${ }^{a}$ 江南大学化学与材料工程学院 无锡 214122) \\ ( ${ }^{b}$ 浙江大学生物质化工教育部重点实验室 杭州 310027)
}

\begin{abstract}
摘要 近年来, 路易斯碱有机小分子催化的亚胺不对称还原反应，因氢源廉价和后处理简单等优点而受到关注. 分别 介绍了甲酰胺类、吡啶酰胺类、亚磺酰胺类、非酰胺类以及负载型路易斯碱有机小分子催化剂在亚胺不对称还原中的 应用, 并且对催化剂的结构特点、催化活性及催化机理等方面展开了论述.

关键词 亚胺; 路易斯碱; 有机催化剂; 不对称还原
\end{abstract}

\section{Progress on the Lewis-Basic Organocatalytic Asymmetric Reduction of Imines}

\author{
Ge, Xin $^{a, b} \quad$ Chen, Xinzhi ${ }^{b} \quad$ Qian, Chao ${ }^{*, b}$ \\ ( ${ }^{a}$ School of Chemical and Material Engineering, Jiangnan University, Wuxi 214122)
}

$\left({ }^{b}\right.$ Key Laboratory of Biomass Chemical Engineering of Ministry of Education, Zhejiang University, Hangzhou 310027)

\begin{abstract}
Recently, the asymmetric reduction of imines catalyzed by Lewis-basic organocatalyst has been received much attention as the cheap hydrogen source and the simple post treatment. Based on the different functional groups of organocatalysts, this paper introduced formamide, pyridine amide, sulfonamide, supported and other Lewis basic organocatalysts. The structural characteristics, catalytic activity and mechanism of the Lewis-basic organocatalysts were summarized.

Keywords imine; Lewis-base; organocatalyst; asymmetric reduction
\end{abstract}

手性化合物除了在生命科学领域有重要用途以外, 它们在农药、香料、食品添加剂及材料科学等领域也引 起人们的普遍关注 ${ }^{[1]}$. 值得注意的是，目前 $40 \% \sim 50 \%$ 手性药物都是手性胺类化合物 ${ }^{[2]}$, 即氨基与手性碳相连 的胺类化合物. 1973 年, Kagan 等 ${ }^{[3]}$ 采用 $\mathrm{Rh}(\mathrm{I})$ 手性磷催 化剂催化 $N$-苄基亚胺的不对称还原反应, 得到 $50 \%$ ee 值的手性胺, 这是文献报道的首例亚胺不对称催化还原 反应. 1991 年, Bakos 等 ${ }^{[4]}$ 将经磺化的 $(2 S, 4 S)-(-)-2,4-$ 双 (二苯基膦)戊烷(BDPP)与 $\mathrm{Rh}(\mathrm{I})$ 配位后得到的催化剂用 于 $N$-苄基亚胺的还原, 在水-有机两相体系中得到了最 高 $96 \%$ ee 的对映选择性, 使得亚胺不对称还原取得了 突破性进展. 之后, 不断涌现出高活性、高选择性的手 性过渡金属亚胺不对称还原催化剂 ${ }^{[5]}$, 包括手性 Ti 催化 剂(Buchwald) ${ }^{[6]}$ Ir-PHOX 催化剂(Pfaltz) ${ }^{[7]} 、$ Ir-f-
Binaphane 催化剂(张绪穆 ${ }^{[8]}$ 和二胺一钉催化剂 ${ }^{[9]}$ 等, 其 中还原应用最成功的是 Ir-Xyliphos 催化剂 ${ }^{[10,11]}$.

与手性过渡金属催化剂相比，最近十几年发展起来 的手性有机小分子催化剂有着自己独特的优势, 因此受 到人们越来越多的重视. 自 2000 年 List ${ }^{[12]}$ 报道脯氨酸催 化的分子间直接不对称羟醛反应以来，基于有机小分子 催化的有机催化反应得到了长足发展, 并表现出诸多优 越性，如：制备简单、价格便宜、性能稳定、条件较温 和、可负载化等. 目前, 手性有机小分子催化已经成为 不对称催化的热门课题. 与利用手性有机小分子催化的 不对称 Aldol 反应 ${ }^{[13,14]} 、$ Mannich 反应 ${ }^{[15]}$ 、Michael 反

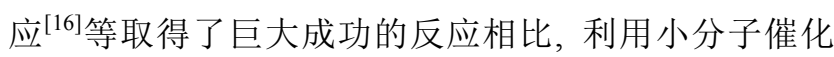
剂催化亚胺的不对称还原反应的研究相对较少. 自 2001 年, Matsumura 等 ${ }^{[17]}$ 首次报道 $N$-甲酰基脯氨酸衍生

\footnotetext{
*E-mail: qianchao@zju.edu.cn

Received December 21, 2015; revised January 26, 2016; published online February 2, 2016

Project supported by the Natural Science Foundation of China (Nos. 21376213, 21476194), Zhejiang Provincial Public Technology Research of China (Nos. 2014C31123, 2015C31038) and the Fundamental Research Funds for the Central Universities (No. JUSRP115A05).

国家自然科学基金(Nos. 21376213, 21476194)、浙江省科技厅公益性技术应用研究计划项目(Nos. 2014C31123, 2015C31038)、江南大学自主科研计划 (No. JUSRP115A05)资助项目.
} 
的有机小分子催化剂催化亚胺的不对称还原后, 目前分 别已有布鲁斯特酸有机小分子催化剂 ${ }^{[18 ~ 21]}$ 和路易斯碱 有机小分子催化剂两大类用于催化亚胺不对称还原的 手性小分子催化剂得到陆续关注和研究, 这两类催化剂 所用的氢源分别是三氯硅烷和 Hantzsch 酯. 路易斯碱有 机小分子利用酰胺羰基与 $\mathrm{Si}$ 原子之间的氢键活化三氯 硅烷中的 $\mathrm{Si}-\mathrm{H}$ 键; 而布鲁斯特酸有机小分子的催化还 原是模拟了自然界氨基酸的生物合成, 是一个催化的氢 转移反应. 两者相比较而言, 三氯硅烷是廉价易得的有 机硅产品, 反应结束后经淬灭、萃取、洗涤等简单操作, 所得的副产物仅仅是 $\mathrm{NaCl}$ 和 $\mathrm{SiO}_{2}$, 易于处理, 对环境 影响小. 因此, 从有机催化目前的发展水平, 以三氯硅 烷为氢源的催化亚胺不对称还原反应更有应用价值.

在路易斯碱有机小分子催化亚胺不对称还原反应 领域, 影响较大的是日本长崎大学的 Matsumura 小组、 英国 Glasgow 大学的 Malkov-Kocovsky 小组和中国科学 院孙健小组和张晓梅小组. 本文根据不同的酰胺官能 团, 将路易斯碱有机小分子催化剂分为甲酰胺类、吡啶 酰胺类、亚磺酰胺类、非酰胺类以及负载型路易斯碱有 机小分子催化剂(Eq. 1).

$$
{ }_{1}^{\mathrm{R}^{1}}
$$

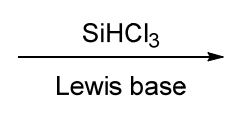

研究学者以此为模板衍生了一系列甲酰胺类的有机小 分子催化剂(Scheme 1). Malkov-Kocovsky ${ }^{[22]}$ 首先用骨架 结构更加柔性的傾氨酸代替脯氨酸, 合成了 $N$-甲基顺 氨酸酰胺类衍生物 4 ; 之后孙健 ${ }^{[23]}$ 等在有机催化剂 3 基 础上设计了 $C_{2}$ 对称的手性四酰胺 $\mathbf{5}$, 后来他们结合了 Matsumura 和 Malkov-Kocovsky 的工作, 认为脯氨酸的 五元环骨架刚性太强而结氨酸的非环骨架刚性太弱, 达 不到更高的对映选择性, 而六元环的骨架刚性适中, 并 由此合成了 $N$-甲酰哌啶酸酰胺类衍生物 $\mathbf{6}^{[24]}$; 继而结合 了更易修饰的哌嗪六元环, 设计了 $N$-甲酰哌嗪酸酰胺 类衍生物 $7^{[25]}$; 之后引入了优良手性模板的二苯基氨基 醇, 分别合成了 $N$-甲酰哌啶酸酰胺类衍生物 8 和 $9^{[26,27]}$. 这些催化剂的发展和改进, 使得亚胺的不对称还原更加 高效、高对映选择. 本节将对甲酰胺类路易斯碱有机小 分子催化剂作详细的介绍.

\section{1 甲酰胺脯氨酸类路易斯碱有机小分子催化剂}

2001 年, Matsumura 等 ${ }^{[17]}$ 从 $L$-脯氨酸出发, 合成了 一系列 $N$-甲酰基脯氨酸衍生物 3 和 $10 \sim 11$, 将其作为路 易斯碱有机小分子催化剂, 用于催化亚胺的不对称还原 胺化反应(Eq. 2). 结果发现 3 表现出较好的对映选择性 (最高 $66 \% \mathrm{ee}$ ), 产物构型为 $R$ 构型. 由此推测了该反应 的过渡态: 三氯硅烷与酰胺的羰基络合, 活化后形成了 两个过渡态 $\mathbf{A}$ 和 $\mathbf{B}$, 由于催化剂上的苯基和底物苯基的 位阻较大, 过渡态 $\mathbf{B}$ 较不稳定, 所以得到主要产物是由 过渡态 $\mathbf{A}$ 得到的 $R$ 构型. 虽然 $N$-甲酰基脯氨酸衍生物 $\mathbf{3}$ 催化的 $e e$ 值不是很高, 但却是首次将有机小分子催化 应用到亚胺的不对称还原中, 后续开发的路易斯碱有机 小分子都是在这基础上进行衍生.

\section{1 甲酰胺类路易斯碱有机小分子催化剂}

自从 Matsumura 等 ${ }^{[17]}$ 设计的 $N$-甲酰基脯氨类有机 小分子催化剂 3 成功地催化亚胺的不对称还原后, 一些<smiles>O=CC1CCCN1C(=O)[C@@H]1CCCN1C(=O)O</smiles>

5

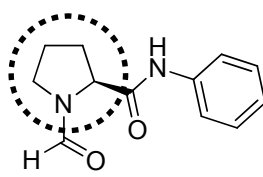

3
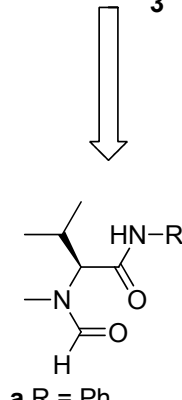

a $\mathrm{R}=\mathrm{Ph}$

b $\mathrm{R}=3,5-\mathrm{Me}_{2} \mathrm{C}_{6} \mathrm{H}_{3}$

c $\mathrm{R}=3,5-(t-\mathrm{Bu})_{2} \mathrm{C}_{6} \mathrm{H}_{3}$

4<smiles>[R]NC(=O)[C@H]1CCCCN1C(=O)[O-]</smiles><smiles>C=CC=C</smiles>

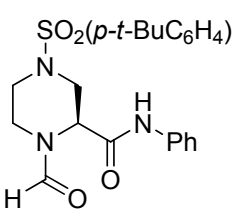

7

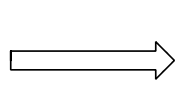<smiles>CC(C)(C)OC(=O)C(NC(=O)N1CCCCC1)C(c1ccccc1)c1ccccc1</smiles>

8
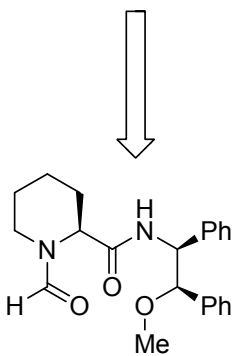

9

图式 1 甲酰胺类路易斯碱有机小分子催化剂的衍生

Scheme 1 Development of amide Lewis-basic organocatalysts 

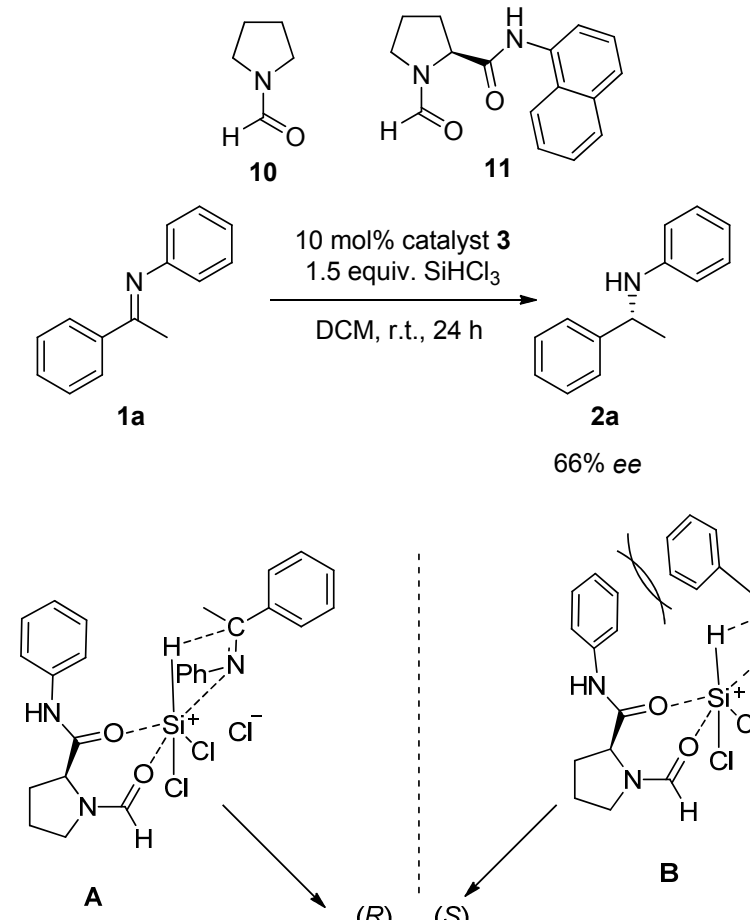

(R)

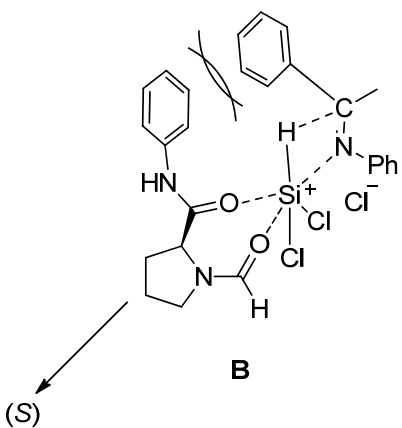

2007 年孙健等 ${ }^{[23]}$ 设计了 $L$-脯氨酸衍生物 $C_{2}$ 对称的 手性四酰胺 5 (Eq. 3), 该催化剂在 $N$-芳基亚胺的还原中, 得到了 $77 \%$ ee 的对映选择性. 同时该催化剂有更广的 底物适应性，在催化还原大位阻的 $N$-芳基非甲基酮亚胺 时，对映选择性均有所提高 $(78 \% \sim 86 \% e e)$.<smiles>CC(=Nc1ccccc1)c1ccccc1</smiles>

1a

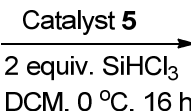
$\mathrm{DCM}, 0^{\circ} \mathrm{C}, 16 \mathrm{~h}$<smiles>CC(Nc1ccccc1)c1ccccc1</smiles>

$77 \%$ ee
2009 年, Schreiner 等 ${ }^{[28]}$ 在 $N$-甲酰基脯氨酸衍生物 3 的基础上，用金刚烷代替 3 的芳香官能团，合成了新的 $N$-甲酰基脯氨酸衍生物, 催化 $N$-芳基亚胺的还原, 取得 了 $68 \% e e$ 的对映选择性. 2012 年 Kanemitsu 等 ${ }^{[29]}$ 用不同 的取代基代替 $N$-甲酰基脯氨酸衍生物 $\mathbf{3}$ 上的甲酰基，合 成了一系列脯氨酸衍生的催化剂 12, 用来催化 $N$-芳基 亚胺的还原, 发现 $N$-特戊酰基脯氨酸衍生物 $12 \mathrm{~h}$ 的催化 活性较高, 其中对映选择性可以提高到 $88 \% e e$, 但是产 物构型为 $S$ 构型(Eq. 4).

\section{2 甲酰胺绵氨酸类路易斯碱有机小分子催化剂}

2004 年, Malkov 等 ${ }^{[22,30 ~ 32]}$ 用倾氨酸替代脯氨酸, 合 成了有机小分子催化剂 $N$-甲基烦氨酸酰胺类衍生物 $\mathbf{4}$, 用来催化 $N$-芳基亚胺的不对称还原，对映选择性为 $92 \%$ (Eq. 5). 研究结果表明柔性的催化剂模板催化效果较好, 而且他们得到的产物构型为 $S$ 构型, 和 $N$-甲酰基脯氨酸<smiles>C/C(=N\c1ccccc1)c1ccccc1</smiles>

1a<smiles>[R]N1CCCC1C(=O)Nc1ccccc1</smiles>

12

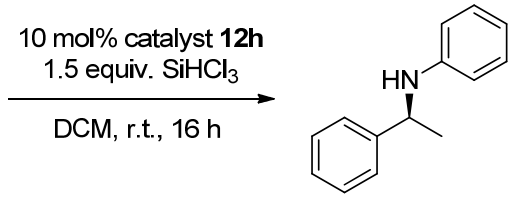

2a

$88 \%$ ee

a: $\mathrm{R}=\mathrm{H}, \mathbf{b}: \mathrm{R}=\mathrm{Cbz}, \mathbf{c}: \mathrm{R}=\mathrm{Fmoc}$

d: $R=B o c, e: R=$ Troc, $\mathbf{f}: R=A c$ g: $R=B z, \mathbf{h}: R=P i v, i: R=$ trichloroacetyl
衍生物 3 得到的构型是相反的, 这主要是因为两者的催 化机理不同导致的. $N$-甲基缬氨酸酰胺类衍生物 $4 \mathrm{~b}$ 的机 理(Eq. 5): 两个酰胺的羰基氧和三氯硅烷络合, 活化了 三氯硅烷，同时线氨酸氨上的甲基对催化剂的催化活性 也起着关键的作用; 另外催化剂的芳香环和底物的芳香 环之间出现 $\pi-\pi$ 交互作用，可以形成稳定的中间过渡， 这是有利于最终产物构型为 $S$ 型; 缴氨酸酰胺的氢与亚 胺的氮原子会形成氢键，从而活化了氮原子. 虽然该类 催化剂催化亚胺不对称还原催化效果较高, ee 值最高可 达 $92 \%$ ，但是 $N$-甲基缅氨酸酰胺类衍生物 $\mathbf{4}$ 也是有局限 性的, 实验结果发现较优的对映选择性仅限于底物中的 氮原子上是芳香基团，如果氮原子上是非芳香基团，则 对映选择性很低 ${ }^{[30]}$.<smiles>CC(=Nc1ccccc1)c1ccccc1</smiles>

1a

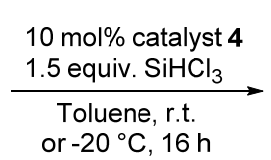
or $-20^{\circ} \mathrm{C}, 16 \mathrm{~h}$

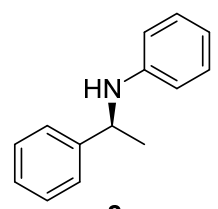

2a up to $92 \%$ ee

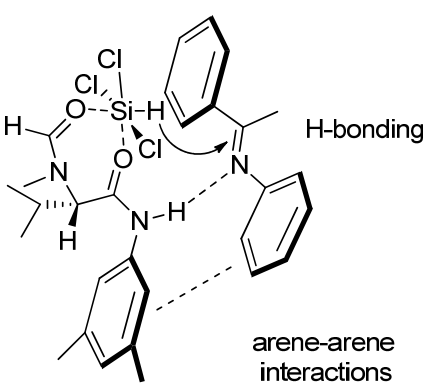

2007 年, Malkov 等 ${ }^{[33]}$ 以 $\alpha$-氯代甲基酮为原料经历 不对称还原胺化合成手性氮丙啶中，采用 $N$-甲基倾氨酸 酰胺类衍生物 $4 \mathrm{~b}$ 和 $4 \mathrm{c}$ 为催化剂, 催化 $\alpha$-氯代芳基亚胺 的不对称还原，对映选择性最高可达 $96 \%$ ee. $\beta$-氨基酸 在医药中有着广泛的应用, $\beta$-氨基酸酯则是制备手性 $\beta$ 氨基酸的主要原料. 2008 年，该小组 ${ }^{[34]}$ 仍旧以 $N$-甲基缬 氨酸酰胺类衍生物 $4 \mathrm{c}$ 作为催化剂, 针对对甲氧基苯基$\beta$-酯基烯胺和 $\beta$-氧基烯胺 15 的不对称还原进行研究, 取 
得较好的收率和对映选择性(Eqs. 6,7).
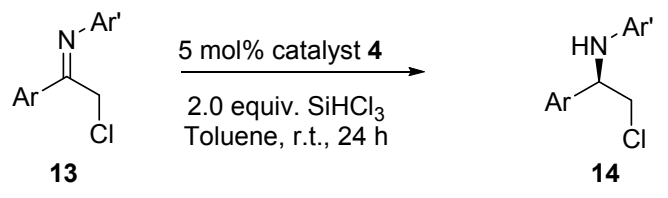

up to $96 \%$ ee

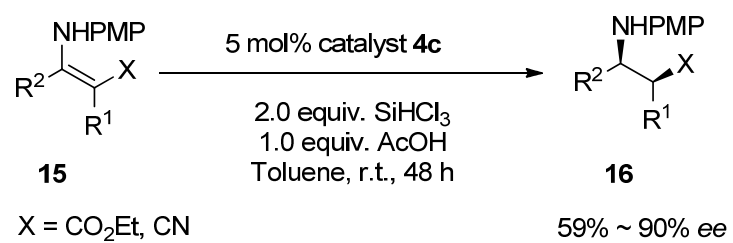

\section{3 甲酰胺哌啶酸类路易斯碱有机小分子催化剂}

2006 年, 孙健等 ${ }^{[26]}$ 在 Matsumura 和 Malkov 工作的 基础上提出: 脯氨酸的五元环骨架刚性太强而缬氨酸的 非环骨架刚性太弱, 造成达不到更高的对映选择性. 因 此, 他们选择刚性居中的六元环为骨架, 从手性哌啶酸 出发, 制备了一系列 $N$-甲酰哌啶酸酰胺类衍生物 $\mathbf{8}$, 可 以高对映选择性地还原 $N$-芳基亚胺(最高 $96 \%$ ee ). 该催 化剂的底物适用性很广, 对于脂肪族酮亚胺, 仍然可以 得到很高的对映选择性( $87 \%$ \% $5 \%$ ee ) ; 尤其对于环己 基酮亚胺, 即便在较为成熟的金属催化体系中, 也只有 少数催化体系可以得到如此的高对映选择性. 2007 年该 课题组 ${ }^{[27]}$ 在 $N$-甲酰哌啶酸酰胺类衍生物 $\mathbf{8}$ 的基础上, 设 计了催化剂 9, 该催化剂可以同时高收率和高选择性的 不对称还原亚胺和酮. 2013 年, 他们 ${ }^{[24]}$ 继续改进了 $N$-甲 酰哌啶酸酰胺类衍生物 8 合成了 $N$-甲酰哌啶酸芳香酰胺 催化剂 19, 对映选择性最高可达 $93 \%$, 但是对于脂肪族 酩亚胺的对映选择性较差(Eq. 8).<smiles>CC(=O)O[C@H](c1ccccc1)C(NC(=O)C1CCCCN1C(C)=O)c1ccccc1</smiles>

8

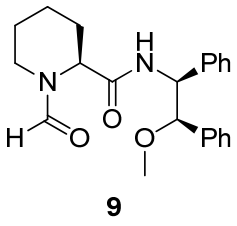

$83 \% \sim 93 \%$ ee

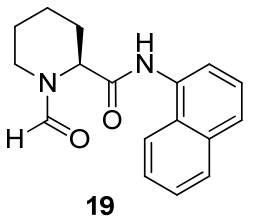

up to $93 \%$ ee
手性二氢吲哚结构具有很强的生物活性, 广泛存在 于天然生物碱和医药中. $3 H$-吲哚的不对称还原是制备 手性二氢吲哚较为重要直接的途径. 2011 年, 孙健等 ${ }^{[35]}$ 用改进的 $N$-甲酰哌啶酸酰胺类衍生物 22, 实现对 $3 H$ -

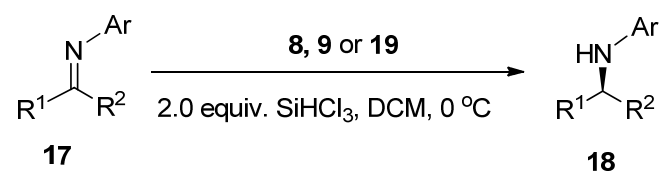

吲哚 20 的不对称还原, 发现质子加入有利于活化 $3 H$ 吲哚, 加入水作为添加剂时, 取得最高为 $93 \%$ ee 的对映 选择性(Eq. 9).

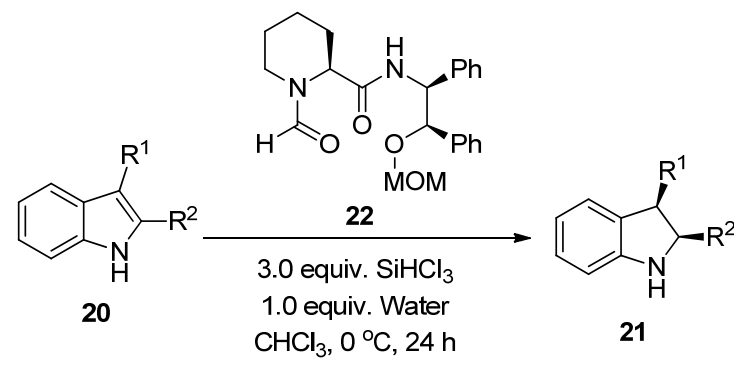

up to $93 \%$ ee

该小组 ${ }^{[25]}$ 在确认了六元环的骨架是催化亚胺还原 的较好模板后, 尝试用六元哌嗪环代替六元哌啶环, 由 于哌嗪的 4 位还有一个氮原子, 六元哌嗪环上具有更大 的修饰空间，由此制备了 $N$-甲酰哌嗪酸酰胺类衍生物 7 , 对于大位阻的 $N$-芳基非甲基酮亚胺可以达 $97 \%$ 的对映 选择性(Eq. 10). 该催化体系对于亚胺氮上的基团很敏 感，苯环上的电子效应对产物的对映选择性影响很大， 苯环上有吸电子基团的收率远高于供电子基团.

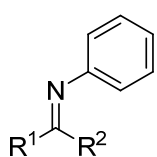

$17 a$

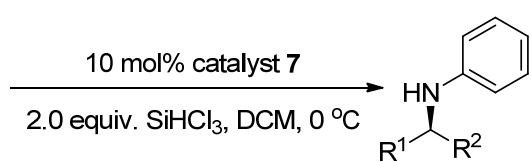

$18 a$

\section{2 吡啶酰胺类路易斯碱有机小分子催化剂}

甲酰胺类路易斯碱有机小分子催化剂的设计主要 是改进催化剂的骨架结构, 与此同时一些研究学者仍旧 以吡咯烷的五元环为骨架, 通过引入官能团来修饰吡咯 烷的五元环, 其中以吡啶酰胺类路易斯碱有机小分子的 发展最为成功.

2006 年, Matsumura 小组 ${ }^{[36]}$ 再次以吡咯烷为骨架, 设计了一类同时带有吡啶、酰胺、羟基三官能团的 $N$ 吡啶酰胺吡咯烷衍生物 23, 用于芳香酮亚胺的不对称还 原反应，所得产物的绝对构型为 $S$ 型，对映选择性最高 可以达到 $80 \%$. 该小组通过实验侧面证明吡啶、酰胺和 羟基共同起着催化作用，吡啶环上的氮原子、酰胺的氧 原子与硅原子络合，活化三氯硅烷，羟基的氢活化亚胺 氮原子, 由于催化剂上苯环和底物苯环位置重叠, 它们 之间的空间位阻使得过渡态 $\mathbf{B}$ 不如过渡态 $\mathbf{A}$ 稳定，反应 的主产物构型以 $S$ 型为主(Eq. 11).

2006 年, 张晓梅等 ${ }^{[37]}$ 将用 3,5-二甲基苯环代替 $N$ 吡啶酰胺吡咯烷衍生物 23 上的苯环, 合成了 $N$-吡啶酰 

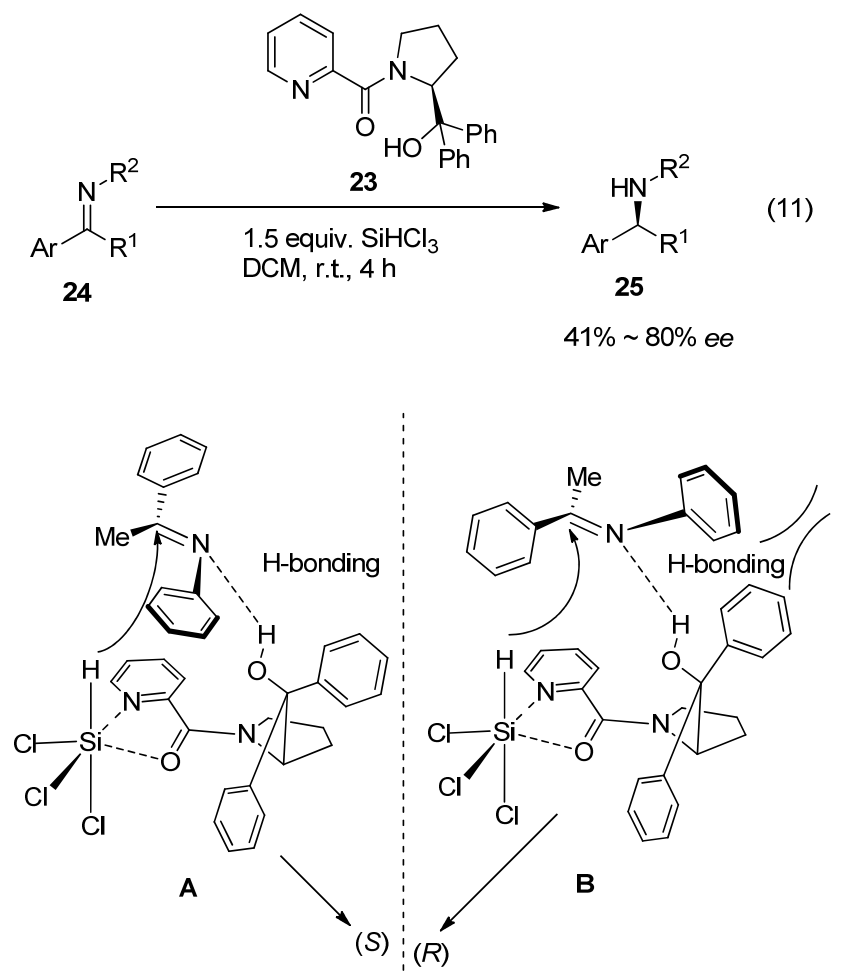

胺吡咯烷衍生物 26, 用来催化 $\beta$-烯胺酸酯类 27 的不对 称还原反应，高对映选择性的得到了各种手性 $\beta$-胺酸酯 类 28 (最高 $96 \% e e$ ), 但是该类催化剂主要适用于 $N$-芳基 芳香酮亚胺(Eq. 12).<smiles>O=C(c1ccccn1)N1CCCC1C(O)([Al])Br</smiles>

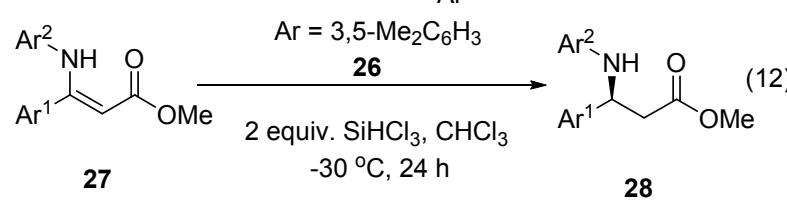

up to $96 \%$ ee

2010 年, 该小组 ${ }^{[38]}$ 尝试将 $N$-吡啶酰胺吡咯烷衍生 物 26 催化 $N$-芳基- $\alpha$-亚胺酸酯类的不对称还原, 但是对 映选择性并不是很高, 因此从反式-4-差基- $L$-脯氨酸出 发合成了新的 $N$-吡啶酰胺吡咯烷衍生物 29, 提供了一 种高对映选择性地制备 $\alpha$-胺酸酯类 31 的方法(最高为 93\% ee). 手性二氢-1,5-苯并二氮杂-2-酮具有多种的生 物活性, 可以用来制备镇静剂和内分泌调节剂. 对苯并 $[b][1,4]$ 二氮杂草-2-酮的不对称还原是获得手性二 氢-1,5-苯并二氮杂-2-酮较为直接的途径. 2011 年, 张晓 梅等 ${ }^{[39]}$ 将 $N$-吡啶酰胺吡咯烷衍生物 29 用于苯并 $[b][1,4]$ 二氮杂草-2-酮的不对称还原，最高可以得到 $97 \% \mathrm{ee}$ 的 对映选择性. 2011 年, 孙健等 ${ }^{[35]}$ 也尝试用该催化剂 29, 实现对 $3 H$-吲哚的不对称还原, 以水作为添加剂时, 取
得最高为 $90 \%$ ee 的对映选择性(Eq. 13).

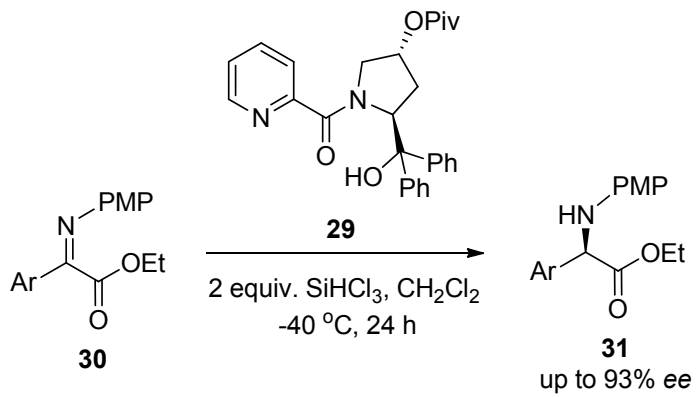

2009 年, Gautier 等 ${ }^{[40]}$ 在 Matsumura 等 ${ }^{[36]}$ 设计的 $N$ 吡啶酰胺吡咯烷衍生物 23 基础上, 将吡啶环换成 $N$-甲 基咪唑环 32, 用于 $N$-芳基亚胺的不对称还原，所得产物 的绝对构型为 $S$ 型，还原产物的 $e e$ 值为 $85 \% .2012$ 年, 林贤福等 ${ }^{[41]}$ 用该催化剂 32 , 在苯甲酸助剂作用下实现 了 $N$-烷基(或芳基)- $\beta$-芳基(或烷基)烯胺酸酯类的不对称 还原，对映选择性最高到 $94 \%$ (Eq. 14).

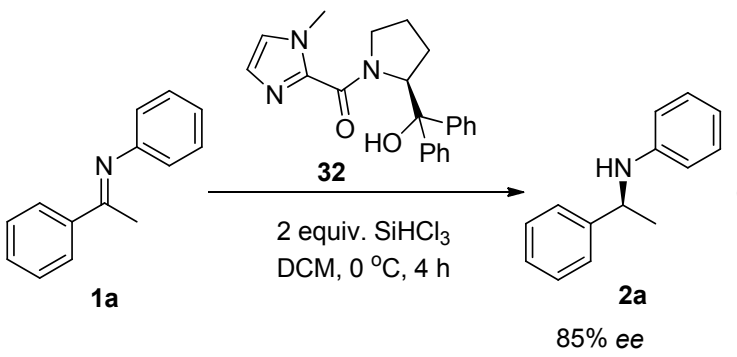

2007 年张晓梅小组 ${ }^{[42]}$ 在 $N$-吡啶酰胺吡咯烷衍生物 基础上，抛弃吡咯环的五元环骨架，采用了更加柔性的 麻黄碱架构, 合成了 $N$-吡啶酰胺麻黄碱类催化剂 33 , 催 化 $N$-芳基亚胺的不对称还原，可以得到 $95 \% \mathrm{ee}$ 的对映 选择性，产物的构型为 $R$ 型. 2008 年，该小组 ${ }^{[37]}$ 尝试用 该催化剂 33 催化 $N$-芳基- $\alpha$-亚胺酸酯类的不对称还原, 还原产物的对映选择性仅有 $72 \%$ ee. 手性二氢苯并啞嗪 酮和二氢喹喔啉具有很高的生物活性，在医药合成中有 着重要的作用. 2010 年张晓梅等 ${ }^{[43]}$ 仍旧使用 $N$-吡啶酰胺 甲基氨基醇类催化剂 33 不对称还原苯并噁嗪酮和喹喔 啉类衍生物，收率均高达 $98 \%$ ，对映选择性分别高达 $97 \%$ ee 和 $93 \%$ ee (Eq. 15).

2011 年，张晓梅等 ${ }^{[44]}$ 以廉价易得的氯霉素中间体 35 为原料，经过两步缩合反应合成制备得到新的吡啶酰 胺类路易斯碱催化剂 37 (Scheme 2), 实现了 $\alpha$-乙酰氧 基- $\beta$-烯胺酯 38 的不对称还原，以 $99 \%$ 的收率、 $93 \%$ 的对 映选择性和 $91: 9$ 的非对映异构体得到相应的 $\alpha$-乙酰氧 基- $\beta$-氨基酸酯类衍生物 39, 并且最终可以合成出紫杉 醇侧链 40 (Scheme 3). 该路易斯碱催化体系的设计新颖 独特, 反应条件温和, 为光学活性 $\alpha$-差基- $\beta$-氨基酸衍生 


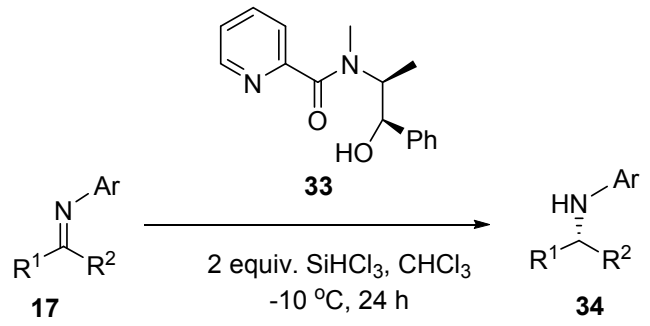

$61 \% \sim 95 \%$ ee

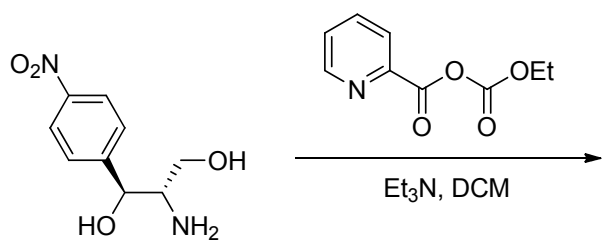

35

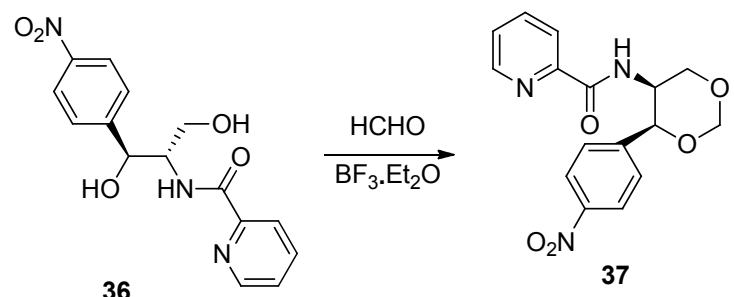

图式 2 路易斯碱有机小分子催化剂 37 的合成

Scheme 2 Synthesis of Lewis-basic organocatalyst 37

物的合成提供了新方法.

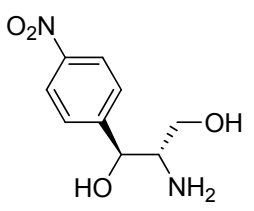

35

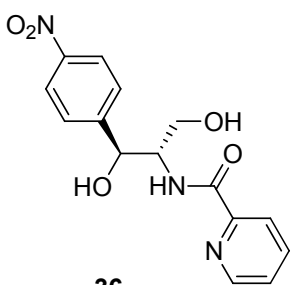

36

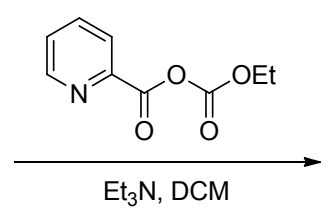

$\underset{\mathrm{BF}_{3} \cdot \mathrm{Et}_{2} \mathrm{O}}{\mathrm{HCHO}}$<smiles>O=C(NC1COCOC1c1ccc([N+](=O)[O-])cc1)c1ccccn1</smiles>

37
图式 3 紫杉醇侧链 $\mathbf{4 0}$ 的合成

Scheme 3 Synthesis of the taxol side chain $\mathbf{4 0}$

2011 年, Guizzetti 等 ${ }^{[45]}$ 在 $N$-吡啶酰胺麻黄碱类催化 剂 33 基础上合成 $N$-(4-氯)吡啶酰胺麻黄碱类催化剂 41, 催化 $N$-苄基- $\beta$-烯胺酸酯类 $\mathbf{4 2}$ 的不对称还原, 获得了最 高 99\% ee 的对映选择性, 然后加氢还原脱除茮基保护, 可以获得烷基(或芳香基) $\beta$-氨基酸酯 44 (Scheme 4).<smiles>[R]C(=CC(=O)O)NC([R])c1ccccc1</smiles>

42

$$
\begin{aligned}
& R^{1}=A r, \text { Alky } \\
& R^{2}=H, M e
\end{aligned}
$$$$
\mathrm{R}^{3}=\mathrm{Me}, t-\mathrm{Bu}
$$

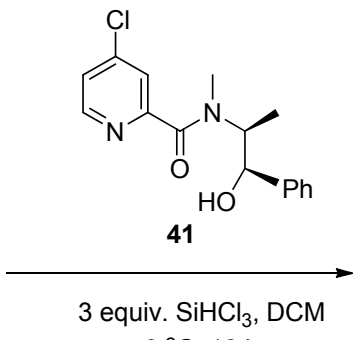

$0{ }^{\circ} \mathrm{C}, 18 \mathrm{~h}$

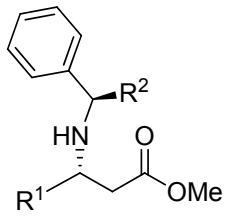

43 up to $99 \%$ ee

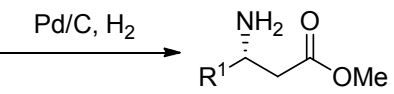

44

图式 $4 \beta$-氨基酸酯 44 的合成

Scheme 4 Synthesis of $\beta$-enamino esters 44

\section{3 亚磺酰胺类路易斯碱有机小分子催化剂}

手性硫氧化物一方面具有优良的手性诱导能力; 另 一方面, 硫原子作为手性中心距离氧更加接近, 作为路 易斯碱可以提高反应的活性和立体控制. 2006 年, 孙健 等 ${ }^{[46]}$ 在此理论基础上以叔丁基亚磺酰胺为骨架, 设计了 单齿 $S$-叔丁基亚磺酰胺类路易斯碱催化剂 45 , 以三氯硅 烷为氢源，用于 $N$-芳香基亚胺的不对称还原反应，证实 了亚磺酰胺基在不对称还原中是重要的基团, 其还原产 物的对映选择性高达 $93 \%$ ee (Eq. 16).

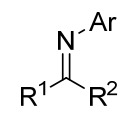

17<smiles>[X]c1ccc(O)c(CNS(=O)C(C)(C)C)c1</smiles>

2 equiv. $\mathrm{SiHCl}_{3}, \mathrm{DCM}$ $-20^{\circ} \mathrm{C}, 4 \mathrm{~h}$<smiles>[R]C([R])N[Al-]</smiles>

2008 年该小组 ${ }^{[47]}$ 针对酚羟基在催化剂中的重要作 用, 推测了反应机理(图 1): 在催化反应中单齿 $S$-叔丁基 亚磺酰胺类路易斯碱催化剂 $\mathbf{4 5}$ 极有可能是通过双分子 机理去活化三氯硅烷，而双分子的链接主要依靠酚羟基 的分子间氢键作用完成的. 因此该小组设计了具有双齿 结构 $S$-叔丁基亚磺酰胺类路易斯碱催化剂 46, 催化用于 $\mathrm{N}$-芳香基亚胺的不对称还原反应，获得高达 $96 \%$ ee 的 对映选择性(Eq. 17).

2008 年孙健小组 ${ }^{[48]}$ 认为亚磺酰胺硫原子上的氧与 酰胺上的氧一样, 都具有路易斯碱的电子特性，同时也 验证了将亚磺酰胺基确实可以催化亚胺的不对称还原. 因此, 将 $S$-叔丁基亚磺酰胺基引入到 $N$-甲酰基脯氨酸衍 


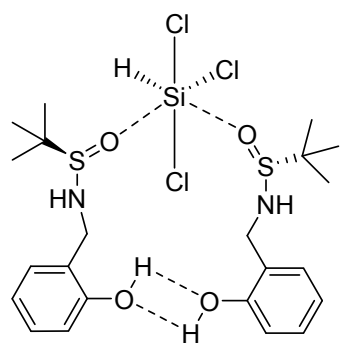

图 145 的双分子催化机理

Figure 1 Proposed binding pattern of $\mathbf{4 5}$

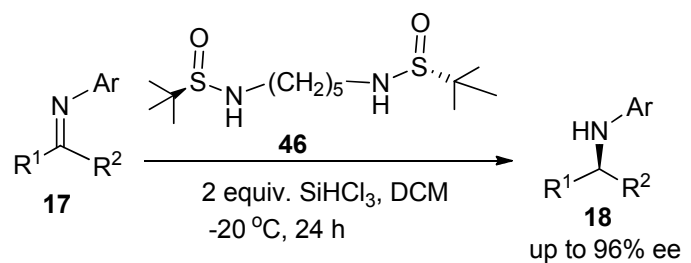

生物 3 中，替代之前的甲酰胺基，设计了 $N-(S)$ 叔丁基亚 磺酰胺基脯氨酸衍生物 $\mathbf{4 7}$, 催化 $N$-烷基亚胺的不对称 还原，对映选择性最高至 $96 \%$ ee (Eq. 18).<smiles>[R]C(=[V])N[AlH2]</smiles>

48

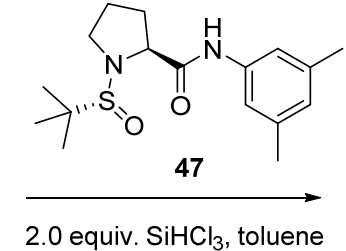

$0^{\circ} \mathrm{C}, 24 \mathrm{~h}$

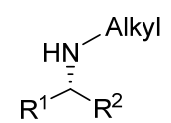
up to $96 \%$ ee

由于不对称还原制备手性 $\beta$-氨基酸具有很大的应 用价值, 2011 年, 孙健等 ${ }^{[49]}$ 将 $N-(S)$ 叔丁基亚磺酰胺基脯 氨酸衍生物 50, 催化 $N$-烷基- $\beta$-脱氢氨基酸酯 51 的不对 称还原, 产物的对映选择性最高为 $97 \% \mathrm{ee}$, 并且发现水 的加入对催化剂活性的提高非常重要(Eq. 19).

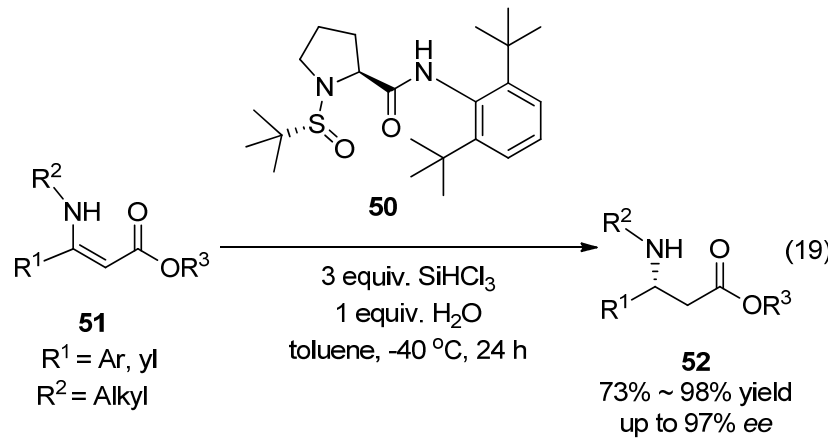

\section{4 非酰胺类路易斯碱有机小分子催化剂}

比较成功的甲酰胺类、吡啶酰胺类和亚磺酰胺类路 易斯碱有机小分子催化剂都属于酰胺类催化体系, 但是
在催化剂发展过程中，一些非酰胺类路易斯碱有机小分 子催化剂也得到了不断发展和重视.

2006 年, Malkov 等 ${ }^{[50]}$ 设计出一种异喹啉-噁唑类的 非酰胺路易斯碱有机小分子催化剂 53, 催化 $N$-芳基亚 胺 17 的不对称还原, 得到高达 $87 \%$ ee 的对映选择性, 产物的构型为 $R$ 型，但是底物仅仅局限于芳香族(Eq. 20). 该小组提出了过渡态的假设(图 2), 硅原子与催化 剂上两个氮原子的孤对电子相配位, 活化了三氯硅烷, 三氯硅烷和催化剂的络合物会选择亚胺位阻小的一侧 进攻; 同时催化剂的吡啶环和底物的芳香环由于 $\pi-\pi$ 交 互作用，也有利于产物的构型 $R$ 型.

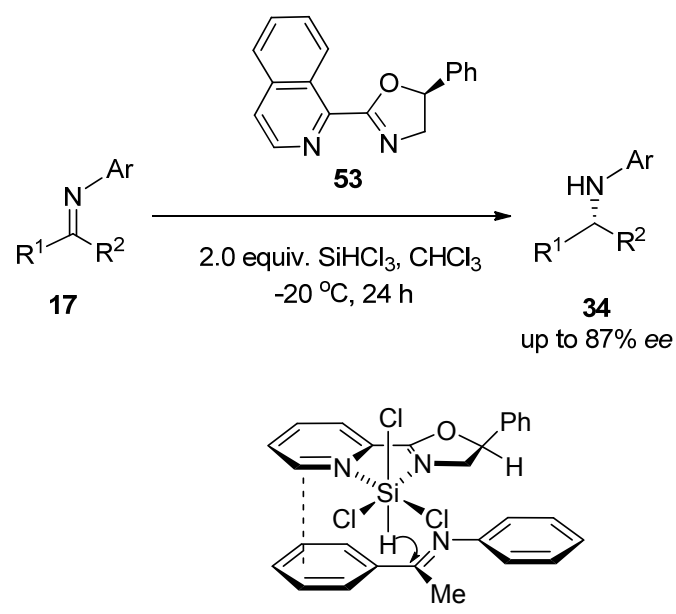

图 2 异喹啉-噁唑类路易斯碱有机小分子催化剂 $\mathbf{5 3}$ 还原亚胺 的可能过渡态

Figure 2 A plausible transition state for imine reduction with $\mathbf{5 3}$

糖也是自然界中很重要的天然产物, 而且糖是含多 个手性中心和多个易于修饰的功能基团而且对环境友 好的有价值的手性源 ${ }^{[51]}$. 同时 $D$-氨基葡萄糖来源广泛， 结构易于修饰，我们 ${ }^{[52]}$ 尝试将吡啶酰基的官能团引入到 糖环结构中合成了糖基吡啶甲酰类的路易斯有机小分 子催化剂 54, 催化 $N$-芳香亚胺的不对称还原, 取得了最 高为 $75 \% e e$ 的对映选择性. 同时分析了可能的过渡态: 吡啶上的氮原子和羰基上的氧原子会与硅原子发生络 合，活化了三氯硅烷，催化剂上的吡啶环会和底物的芳 香环之间出现 $\pi-\pi$ 交互作用，有利于形成稳定的过渡态; 加上糖环本身具有特殊的空间结构，糖环上 2 位的酰基 上的氢会与亚胺的氮原子形成氢键, 这些因素叠加会有 利于最终产物构型为 $S$ 型(Eq. 21).

\section{5 负载型路易斯碱有机小分子催化剂}

在有机小分子催化亚胺的不对称还原反应中，反应 物、产物和催化剂均为有机小分子，目标产物分离较困 难，特别是催化剂不易回收循环利用. 将有机小分子催 化剂通过负载嫁接在可以回收的材料上，可以有效地解 


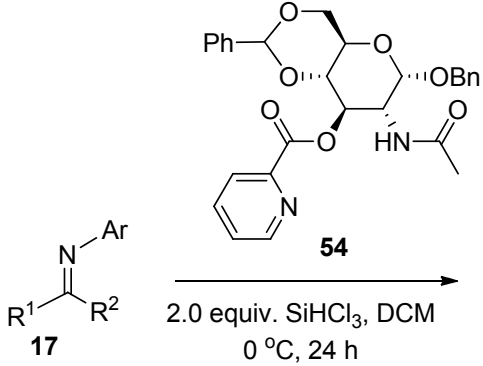

决催化剂的分离回收问题. 制备负载型催化剂并且要其 保持在均相催化剂中立体选择性一直是催化领域研究 的热点. 有机小分子催化剂的负载有利于有机小分子的 回收利用和反应后处理纯化等. 目前主要的载体是聚合 物、硅胶和磁性纳米粒子等.

2007 年, Malkov 等 ${ }^{[53]}$ 制备了负载于氟碳标记基团 (Fluorous tag)上的 $N$-甲基顺氨酸酰胺类有机催化剂 $\mathbf{5 5}$, 催化 $N$-芳基亚胺的不对称还原反应, 产物的对映选择性 最高为 $95 \% e e$. 催化剂的分离和回收也较为方便, 使用 氟化硅胶吸附催化剂 $\mathbf{5 5}$, 实现催化剂和反应液的分离, 然后用甲醇洗脱回收催化剂 55. 但是该方法催化剂的损 耗还是很高，回收率较低时只有 $70 \%$, 而且催化剂的反 应活性和对映选择性均有不同程度的下降(Eq. 22).
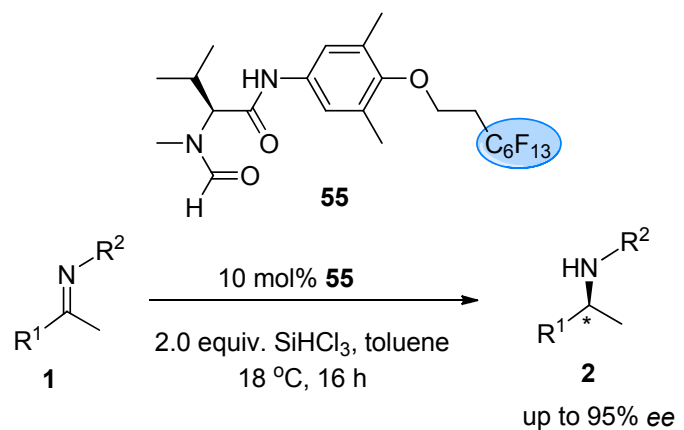

2008 年, Malkov 等 ${ }^{[54]}$ 制备了基于 Merrifield 树脂的 $N$-甲基缬氨酸酰胺类有机催化剂 56, 该催化剂回收更加 方便，但是催化剂的对映选择性不到 $80 \% \mathrm{ee}$, 催化剂的 活性也出现明显下降.

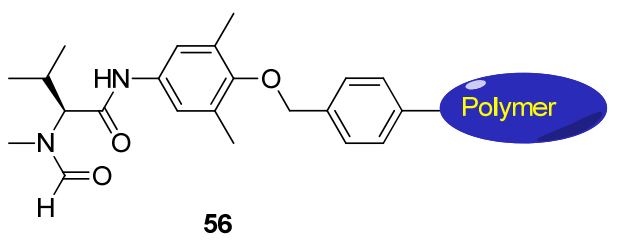

对于多相催化剂, 一般反应物向催化剂表面的扩散 速率由催化剂的粒径决定的, 催化剂粒径越大扩散越 慢，同时扩散速率又是反应的速控步骤，所以一般的负 载都是以牺牲催化剂的活性才解决催化剂回收困难的 问题. 采用纳米粒子负载有机小分子催化剂可以解决反

应的扩散和传质问题. 2009 年, Malkov ${ }^{[55]}$ 将 $N$-甲基缴氨 酸酰胺类有机小分子负载在纳米金粒子上，制备了负载 型有机催化剂 57, 该催化剂的活性和对映选择性明显高 于负载有机催化剂 $\mathbf{5 7}$, 对映选择性最高为 $84 \%$, 但是催 化剂循环使用至第 4 次，催化剂的活性开始出现明显下 降. 主要原因是多次使用后会出现催化剂明显从纳米粒 子上脱离的情况, 而且纳米粒子之间团聚情况也非常严 重.

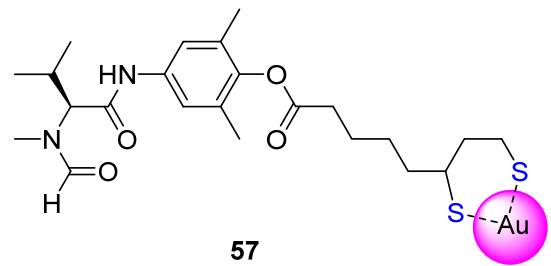

为了解决上述问题, 2009 年, Malkov 等 ${ }^{[56]}$ 放弃了之 前将有机催化剂最后单独负载在载体上的策略, 在 $N$-甲 基缬氨酸酰胺类有机催化剂 58 上接入甲基丙烯酸酯官 能团，然后与甲基丙烯酸酯的单体 60 发生共聚，制备了 基于可溶性载体的有机催化剂 61 (Scheme 5), 该负载型 催化剂 61 可溶于甲苯等非极性溶剂中，但是在甲醇等 极性溶剂会析出, 由此有效解决了传质和回收的问题. 该催化剂催化 $N$-芳基亚胺的不对称还原反应，对映选择 性可达 $86 \%$, 循环多次后催化剂的活性和对映选择性没 有出现下降.<smiles></smiles>
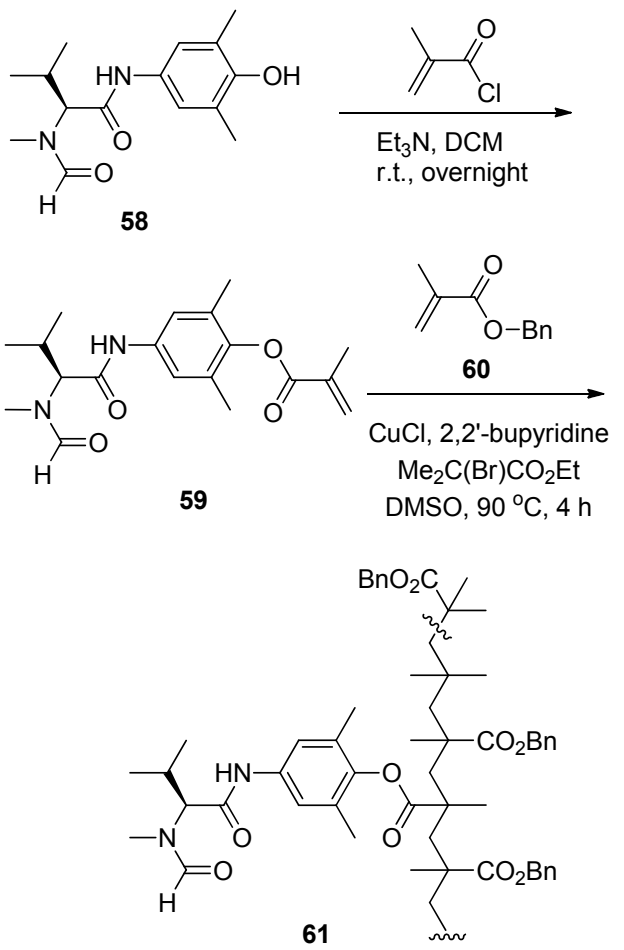

图式 5 基于可溶性载体的有机催化剂 $\mathbf{6 1}$ 的制备 Scheme 5 Synthesis of the soluble supported catalyst 61 
2014 年, 我们 ${ }^{[57]}$ 尝试将 $N$-甲基缬氨酸酰胺类有机 催化剂链接在单糖上, 首先将 $D$-氨基葡萄糖盐酸盐(62) 上的 2 位氨基转化成叠氮, 在经过乙酰化保护得到葡萄 糖叠氮四乙酸酯 63. 将其和炔基衍生的 $N$-甲基烦氨酸 酰胺有机小分子 64 用点击反应制备了糖基的缬氨酸类 有机小分子催化剂 65 (Scheme 6), 将该催化剂用于催化 $N$-芳香亚胺的不对称还原胺化反应，ee 值最高为 $94 \%$, 将该催化剂回收利用, 有机催化剂的活性和对映选择性 没有出现明显下降. 后续可以将 $N$-甲基坃氨酸类有机小 分子逐步嫁接在多糖上, 最后将其负载在壳聚糖等天然 载体.
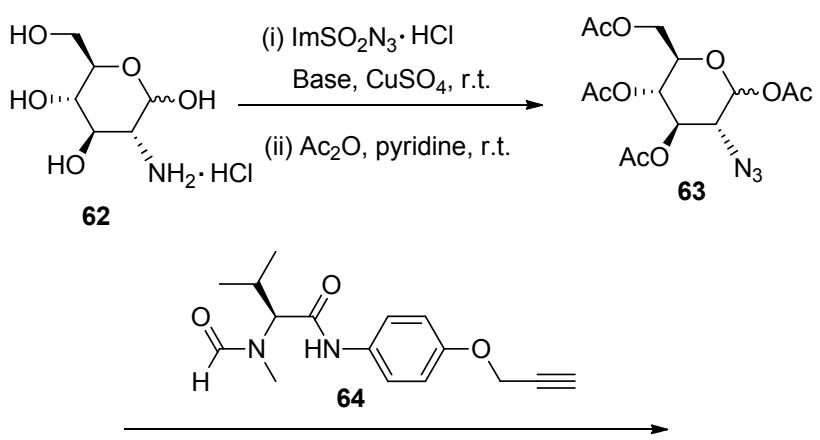

Cul, DIPEA, DMF, $100^{\circ} \mathrm{C}$<smiles>CC(=O)OCC1O[C@H](n2cc(COc3c(C)cc(NC(=O)C(C(C)C)N(C)C(C)=O)cc3C)nn2)[C@H](OC(C)=O)C(OC(C)=O)[C@@H]1O</smiles>

65

图式 6 糖基的缅氨酸类有机小分子催化剂 65 的制备 Scheme 6 Synthesis of carbohydrate-derived organocatalysts 65

近年来, 磁性纳米材料在有机小分子催化剂中的应 用得到了广泛的关注 ${ }^{[58]}$. 这主要是因为磁性纳米粒子是 结合了纳米材料和磁性材料优点的新型功能材料. 一方 面材料尺寸是纳米级, 可以均匀分散在溶剂中, 加快反 应物的传质和扩散; 另一方面材料本身具有的磁性, 可 以使其在外加磁场的作用下，从反应体系中快速分离出 来以便循环使用. 2015 年, 我们 ${ }^{[59]}$ 选用磁性纳米材料 $\mathrm{Fe}_{3} \mathrm{O}_{4}$, 在其表面引入叠氮基, 通过点击化学, 将 $N$-甲基 缬氨酸的酰胺有机小分子 66 通过三氮唑负载在纳米 $\mathrm{Fe}_{3} \mathrm{O}_{4}$ 上, 得到了磁性纳米粒子负载的缬氨酸类有机催 化剂 67 (Scheme 7), 催化不对称还原反应合成手性胺, 对映选择性可以高达 $89 \%$, 循环 5 次后催化剂活性和对 映选择性都没有出现明显下降, 并且使用磁力就可以快 速分离催化剂.
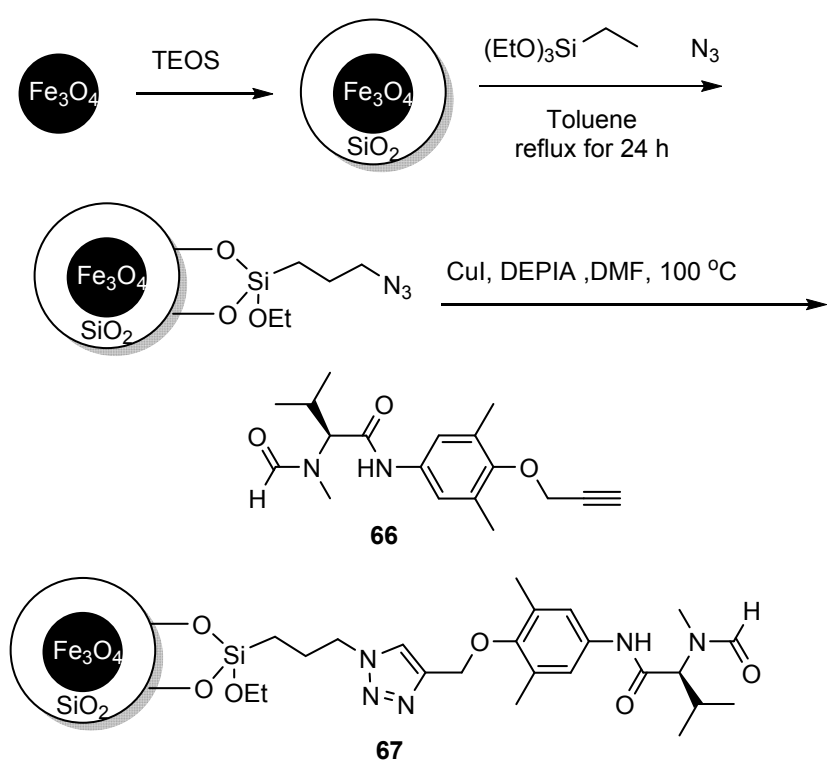

图 7 磁性纳米粒子负载的缅氨酸类有机催化剂 67 的制备 Scheme 7 Synthese of valine derived organocatalyst supported onto MNPs 67

\section{6 结语}

近十多年来, 路易斯碱有机小分子催化剂表现出制 备简单、性能稳定和反应条件温和等优点, 受到了极大 关注, 在亚胺的不对称还原中取得了重大进展. 以 $N$-甲 酰基脯氨酸衍生物为模板, 逐渐衍生了各种高活性、高 对映选择性的有机催化剂, 并且在一些有挑战性的亚胺 底物中得到成功应用. 但是目前的路易斯碱有机小分子 催化剂仍旧存在适用性差、催化剂回收困难等问题. 催 化的底物主要集中在芳香酮亚胺和 $N$-芳香基亚胺，对于 脂肪类亚胺的对映选择性往往较差.

负载型路易斯碱有机小分子催化剂的发展，使亚胺 的不对称还原更加绿色环保，也为工业应用提供了基 础. 然而, 这些负载的方法主要缺陷就是催化剂活性和 对映选择性下降明显. 因此，发展更加高效、适用性广、 环境友好的路易斯碱有机小分子催化剂，是以后亚胺不 对称还原发展的主要方向，对其工业化应用也有更大的 意义.

\section{References}

[1] Lin, G. Q.; Li, Y. M.; Chan, A. S. C. Principles and Applications of Asymmetric Synthesis, Wiley, New York, 2001.

[2] Blaser, H. U. Chem Commun. 2003, 293.

[3] Langlois, N.; Dang, T.; Kagan, H. B. Tetrahedron Lett. 1973, 4865.

[4] Bakos, J.; Orosz, A.; Heil, B.; Laghmari, M.; Lhoste, P.; Sinou, D. J. Chem.Soc.-Chem. Commun. 1991, 1684.

[5] Wang, D.; Hou, C. J.; Chen, L. F.; Liu, X. N.; An, Q. D.; Hu, X. P. Chin. J. Org. Chem .2013, 33, 1355 (in Chinese).

(王东，侯传金，陈丽风，刘小宁，安庆大，胡向平，有机化学， 2013, 33, 1355.)

[6] Willoughby, C. A.; Buchwald, S. L. J. Am. Chem. Soc. 1992, 114, 
7562.

[7] Schnider, P.; Koch, G.; Pretot, R.; Wang, G. Z.; Bohnen, F. M.; Kruger, C.; Pfaltz, A. Chem-Eur J. 1997, 3, 887.

[8] Xiao, D. M.; Zhang, X. M. Angew. Chem., Int. Ed. 2001, 40, 3425.

[9] Wang, C.; Villa-Marcos, B.; Xiao, J. L. Chem. Commun. 2011, 47, 9773.

[10] Blaser, H. U.; Buser, H. P.; Coers, K.; Hanreich, R.; Jalett, H. P.; Jelsch, E.; Pugin, B.; Schneider, H. D.; Spindler, F.; Wegmann, A. Chimia 1999, 53, 275.

[11] Blaser, H. U.; Malan, C.; Pugin, B.; Spindler, F.; Steiner, H.; Studer, M. Adv. Synth. Catal. 2003, 345, 103.

[12] List, B. J. Am. Chem. Soc. 2000, 122, 9336.

[13] List, B.; Lerner, R. A.; Barbas, C. F. J. Am. Chem. Soc. 2000, 122, 2395.

[14] List, B.; Pojarliev, P.; Castello, C. Org. Lett. 2001, 3, 573.

[15] Mitsumori, S.; Zhang, H.; Cheong, P. H. Y.; Houk, K. N.; Tanaka, F.; Barbas, C. F. J. Am. Chem. Soc. 2006, 128, 1040.

[16] List, B.; Pojarliev, P.; Martin, H. J. Org. Lett. 2001, 3, 2423.

[17] Iwasaki, F.; Onomura, O.; Mishima, K.; Kanematsu, T.; Maki, T.; Matsumura, Y. Tetrahedron Lett. 2001, 42, 2525.

[18] Hoffmann, S.; Seayad, A. M.; List, B. Angew. Chem., Int Ed. 2005, $44,7424$.

[19] Rueping, M.; Antonchick, A. P.; Theissmann, T. Angew. Chem., Int. Ed. 2006, 45, 6751.

[20] Rueping, M.; Antonchick, A. R.; Theissmann, T. Angew Chem., Int. Ed. 2006, 45, 3683 .

[21] Rueping, M.; Theissmann, T.; Antonchick, A. P. Synlett 2006, 1071.

[22] Malkov, A. V.; Mariani, A.; MacDougall, K. N.; Kocovsky, P. Org. Lett. 2004, 6, 2253.

[23] Wang, Z. Y.; Wei, S. Y.; Wang, C.; Sun, J. Tetrahedron: Asymmetry 2007, 18, 705 .

[24] Wang, Z. Y.; Wang, C.; Zhou, L.; Sun, J. Org. Biomol. Chem. 2013, 11,787 .

[25] Wang, Z. Y.; Cheng, M.; Wu, P. C.; Wei, S. Y.; Sun, J. Org. Lett. 2006, 8,3045 .

[26] Wang, Z. Y.; Ye, X. X.; Wei, S. Y.; Wu, P. C.; Zhang, A. J.; Sun, J. Org. Lett. 2006, 8, 999.

[27] Zhou, L.; Wang, Z. Y.; Wei, S. Y.; Sun, J. Chem. Commun. 2007, 2977.

[28] Zhang, Z. G.; Rooshenas, P.; Hausmann, H.; Schreiner, P. R. Synthesis-Stuttgart 2009, 1531.

[29] Kanemitsu, T.; Umehara, A.; Haneji, R.; Nagata, K.; Itoh, T. Tetrahedron 2012, 68, 3893.

[30] Malkov, A. V.; Stoncius, S.; MacDougall, K. N.; Mariani, A.; McGeoch, G. D.; Kocovsky, P. Tetrahedron 2006, 62, 264.

[31] Malkov, A. V.; Vrankova, K.; Sigerson, R. C.; Stoncius, S.; Kocovsky, P. Tetrahedron 2009, 65, 9481.

[32] Malkov, A. V.; Vrankova, K.; Stoncius, S.; Kocovsky, P. J. Org. Chem. 2009, 74, 5839 .

[33] Malkov, A. V.; Stoncius, S.; Kocovsky, P. Angew. Chem., Int Ed. $\mathbf{2 0 0 7}, 46,3722$.

[34] Malkov, A. V.; Stoncius, S.; Vrankova, K.; Arndt, M.; Kocovsky, P.
Chem. Eur. J. 2008, 14, 8082 .

[35] Xiao, Y.-C.; Wang, C.; Yao, Y.; Sun, J.; Chen, Y.-C. Angew. Chem., Int. Ed. 2011, 50, 10661.

[36] Onomura, O.; Kouchi, Y.; Iwasaki, F.; Matsumura, Y. Tetrahedron Lett. 2006, 47, 3751.

[37] Zheng, H.-J.; Chen, W.-B.; Wu, Z.-J.; Deng, J.-G.; Lin, W.-Q.; Yuan, W.-C.; Zhang, X.-M. Chem-Eur J. 2008, 14, 9864.

[38] Xue, Z.-Y.; Jiang, Y.; Yuan, W.-C.; Zhang, X.-M. Eur. J. Org. Chem. 2010, 616 .

[39] Chen, X.; Zheng, Y.; Shu, C.; Yuan, W.; Liu, B.; Zhang, X. J. Org. Chem. 2011, 76, 9109.

[40] Gautier, F. M.; Jones, S.; Martin, S. J. Org. Biomol. Chem. 2009, 7, 229.

[41] Jones, S.; Li, X. F. Tetrahedron 2012, 68, 5522.

[42] Zheng, H.; Deng, J.; Lin, W.; Zhang, X. Tetrahedron Lett. 2007, 48, 7934.

[43] Xue, Z.-Y.; Jiang, Y.; Peng, X.-Z.; Yuan, W.-C.; Zhang, X.-M. Adv. Synth. Catal. 2010, 352, 2132.

[44] Jiang, Y.; Chen, X.; Zheng, Y.; Xue, Z.; Shu, C.; Yuan, W.; Zhang, X. Angew. Chem., Int. Ed. 2011, 50, 7304.

[45] Guizzetti, S.; Benaglia, M.; Bonsignore, M.; Raimondi, L. Org. Biomol. Chem. 2011, 9, 739.

[46] Pei, D.; Wang, Z.; Wei, S.; Zhang, Y.; Sun, J. Org. Lett. 2006, 8, 5913.

[47] Pei, D.; Zhang, Y.; Wei, S. Y.; Wang, M.; Sun, J. Adv. Synth. Catal. 2008, 350, 619 .

[48] Wang, C.; Wu, X.; Zhou, L.; Sun, J. Chem. Eur. J. 2008, 14, 8789.

[49] Wu, X. J.; Li, Y.; Wang, C.; Zhou, L.; Lu, X. X.; Sun, J. A. Chem. Eur. J. 2011, 17, 2846.

[50] Malkov, A. V.; Liddon, A.; Ramirez-Lopez, P.; Bendova, L.; Haigh, D.; Kocovsky, P. Angew Chem., Int. Edit .2006, 45, 1432.

[51] Song, S. S.; Zhou, H. Y.; Li, X. N.; Wang, L. H.; Li, Y. Q.; Wang, J. X. Chin. J. Org. Chem. 2014, 34, 706 (in Chinese).

(宋沙沙, 周宏勇, 李小娜, 王丽华, 李云庆, 王家喜, 有机化学, 2014, 34, 706.)

[52] Ge, X.; Qian, C.; Chen, Y. B.; Chen, X. Z. Tetrahedron: Asymmetry 2014, 25, 596.

[53] Malkov, A. V.; Figlus, M.; Stoncius, S.; Kocovsky, P. J. Org. Chem. 2007, 72, 1315.

[54] Malkov, A. V.; Figlus, M.; Kocovsky, P. J. Org. Chem. 2008, 73, 3985.

[55] Malkov, A. V.; Figlus, M.; Cooke, G.; Caldwell, S. T.; Rabani, G.; Prestly, M. R.; Kocovsky, P. Org. Biomol. Chem. 2009, 7, 1878.

[56] Malkov, A. V.; Figlus, M.; Prestly, M. R.; Rabani, G.; Cooke, G.; Kocovsky, P. Chem. Eur. J. 2009, 15, 9651.

[57] Ge, X.; Qian, C.; Chen, X. Z. Tetrahedron: Asymmetry 2014, 25, 1450.

[58] Yuan, D. Z.; Huang, B. Chin. J. Org. Chem. 2012, 32, 1368 (in Chinese).

(袁定重, 黄斌, 有机化学, 2012, 32, 1368.)

[59] Ge, X.; Qian, C.; Ye, X. M.; Chen, X. Z. RSC Adv. 2015, 5, 65402. 